\title{
WORKING
}

paper

\section{Monetary Policy and Digital Currencies: Much Ado about Nothing?}

\author{
Christian Pfister ${ }^{1}$
}

September 2017, WP \# 642

\begin{abstract}
In spite of a still very low volume at the global level, in comparison with the main reserve currencies, digital currencies attract a lot of attention. The paper reminds that it is above all the exchange mechanism incorporated in digital currencies (the distributed ledger technology) which should contribute to their success. It is shown that a widespread use of these currencies is likely to materialize only under conditions that would essentially leave unchanged the capacity of the central bank to pursue the same inflation target using the same instruments as today, by setting an interest rate level. However, some adjustments may have to be made to the definition of monetary aggregates and possibly also to the base and/or the ratios of reserve requirements. Even in the most extreme and unlikely scenario, where the central bank would issue CBDC the public would have access to and massively adopt, banks' role in distributing credit would likely not be seriously impaired. Banks might rather have less direct information on their clients. They would possibly also become more dependent on central bank refinancing, which would call for a clear and pre-announced lending of last resort policy in order to limit moral hazard considerations.
\end{abstract}

Keywords: Digital currencies, Money, Monetary policy

JEL classification: E42 E52 E58

\footnotetext{
${ }^{1}$ Banque de France, christian.pfister@banque-france.fr. I thank David Andolfatto, Emmanuelle Assouan, Michael Bordo, Marion Chich, Françoise Drumetz, Thierry Fasquelle, Pierre Jaillet, Audrey Metzger and Didier Warzee for their remarks. I am sole responsible for any error.
}

Working Papers reflect the opinions of the authors and do not necessarily express the views of the Banque de France. This document is available on publications.banque-france.fr/en 


\section{NON-TECHNICAL SUMMARY}

This paper investigates the possible consequences of digital currencies (DCs) for monetary policy, referring to "digital currencies" as "crypto-currencies". DCs are viewed as a combination of two elements: an asset and an exchange mechanism which allows payment and settlement through the use of distributed ledger technology (DLT). A DL is a bookkeeping system which can be shared ("distributed") and updated in real time via a network of "nodes" (i.e. computers) in a secured manner. DC schemes operate along two different designs: public systems, which incorporate an embedded currency, like the Bitcoin, and private systems which do not necessarily incorporate an embedded currency but always involve a DL.

Motives for a wider usage of DCs could differ between the public and financial institutions. As far as the public is concerned, there are three main reasons for holding DCs: they allow making transactions can be made under pseudonyms, thus helping preserve privacy, like currency already does; they can be used to make relatively cheap and speedy payments at the global level, although this does not seem to be frequent; above all, they can be acquired for speculative motives or to evade capital controls. However, DCs currently perform very poorly the three functions associated with money (medium of exchange, unit of account and store of value), which limits their greater usage. By comparison, the use of DL technology by financial institutions, within private DC schemes, is usually deemed far more promising to the extent that the cost of validating transactions can be kept sufficiently low.

Three main scenarios in which the usage of DCs could become widespread are described and their respective likelihoods in the medium to long-term qualitatively assessed. In a first scenario, labeled A, financial institutions would use DCs only internally and between them, within private DC schemes. This scenario is seen likely, provided some technical issues are solved, and as having very limited monetary consequences. In a second scenario, labeled B, there would be a convergence of DC schemes and banking activities, with DC schemes collecting deposits and distributing credit and/or banks issuing DCs. In both cases, the monetary consequences would vary according to the services provided by DCs: with minimum payment services provided, DCs could substitute for paper currency and unremunerated sight deposits; if DL technology enabled paying interest on DCs, they could also substitute for remunerated sight deposits and term deposits. Scenario B is seen as rather unlikely or at least remote. In a third scenario, labeled $\mathrm{C}$, the central bank itself would issue central bank DC (CBDC). The monetary consequences of scenario $\mathrm{C}$ would at least partly undo and at most reverse those of scenario $\mathrm{B}$. They would depend on who can have access to $\mathrm{CBDC}$ but also, as in $\mathrm{B}$, on the services provided by CBDC. In line with scenario $\mathrm{A}$, a CBDC accessible only to financial institutions is seen as rather likely and would also have limited monetary consequences. A CBDC providing minimum payment services and accessible to the public is seen as unlikely, with more serious monetary consequences. A CBDC providing full banking services is seen as extremely unlikely as the central bank would then compete with commercial banks, with potentially also more serious monetary consequences. The three scenarios and their respective likelihoods are summarized in the table below.

In order to assess the consequences for monetary policy, a distinction is drawn between consequences for monetary policy strategy, conduct and instruments. Regarding strategy, the risks that the widespread use of DCs could inflict a deflationary bias in a growing economy, prevent the smoothing of the business cycle or cause monetary policy lose its potency are overdone since they are predicated on the assumption that DCs would be widely adopted by the public although the inelasticity of their supply makes them clearly unfit as monies. Such risks could only materialize if sovereign currencies were hit by a major credibility loss. Regarding the conduct of monetary policy, the informative content of monetary aggregates could be transitorily reduced but the 
definition of these aggregates could be redefined to encompass DCs, restoring their usefulness as monetary policy indicators. There could also be one-time and limited changes in the monetary policy transmission mechanism. However, CBDC would not enable the central bank to set negative interest rates more easily than today, unless currency is withdrawn or an exchange rate is set for it. Finally, also in scenario C, the role of the central bank as a lender of last resort (LoLR) could be enlarged due to the enhanced substitutability between central bank's and commercial banks' liabilities and, in the very unlikely case the central bank would choose to compete with the banking sector and the public would approve, the increased dependence of bank on central bank refinancing. This would call for making access to LoLR operations more rule-based in order to limit moral hazard considerations. Regarding monetary policy instruments, the central bank would have various possibilities to react to a possible reduction of the demand for reserves and could also choose to implement monetary policy by withdrawing rather than supplying liquidity. In scenario $\mathrm{C}$, the central bank would also have to choose a rate of remuneration for CBDC.

Overall, the consequences for monetary policy of the use of DCs should thus be limited, unless the central bank chose to compete with the banks. However, the decision to embark into the latter project would be highly political and would not necessarily be accepted by the public.

\section{Politique monétaire et monnaies digitales : beaucoup de bruit pour rien?}

\section{RÉSUMÉ}

En dépit d'un encours global encore très faible par rapport à ceux des grandes monnaies de réserve, les monnaies digitales attirent beaucoup l'attention. Ce document rappelle que c'est avant tout le mécanisme d'échange incorporé aux monnaies digitales (la technologie du registre distribué) qui devrait en faire le succès. Il montre qu'un usage répandu de ces monnaies n'a des chances de se produire que dans des conditions qui laisseraient foncièrement inchangées la capacité de la banque centrale à poursuivre un objectif d'inflation identique par les mêmes moyens que de nos jours, en fixant un niveau de taux d'intérêt. Néanmoins, quelques ajustements pourraient devoir être apportés à la définition des agrégats monétaires ainsi éventuellement qu’à la base et/ou aux ratios de réserves obligatoires. Même dans le cas extrême et très improbable où la banque centrale émettrait de la monnaie digitale accessible au public et où celui-ci l'adopterait massivement, le rôle des banques dans la distribution de crédit ne devrait pas être gravement compromis. Les banques pourraient toutefois disposer de moins d'information directe sur les clients tandis que l'importance éventuelle du refinancement par la banque centrale dans les ressources des banques devrait inciter celle-ci à énoncer clairement une politique de prêteur en dernier ressort pour limiter le risque moral.

Mots-clés : Monnaies digitales, Monnaie, Politique monétaire

Les Documents de travail reflètent les idées personnelles de leurs auteurs et n'expriment pas nécessairement la position de la Banque de France. Ce document est disponible sur publications.banque-france.fr 
At the beginning of 2017, there were more than 500 digital currencies (DCs) with a total market value of $\$ 16.8$ billion - or $€ 16$ billion - and Bitcoin, launched in early 2009 , accounting for around $85 \%$ of the market (Cecchetti and Schoenholtz, 2017). In comparison, currency in circulation at the end of 2016 amounted to $€ 1150$ billion, or 72 times more, for the sole single currency. However, some authors have suggested that the increased usage of DCs might, at some point and under certain circumstances, have far-reaching consequences on the banking sector and on the conduct and effectiveness of monetary policy (Broadbent, 2016; Raskin and Yermack, 2016; Bordo and Levin, 2017). Under the same assumption as previous papers that monetary policy consequences would be material only if the usage of DCs was widespread, this paper takes a more nuanced view. The first section reminds the main features of DCs and looks into the motives that might lead to a wider usage of DCs. The second section describes scenarios under which a widespread usage could materialize and their monetary policy consequences. The third section concludes.

\section{Digital currencies, main features and motives for their usage}

\subsection{Main features of digital currencies}

In this paper, in line with BIS publications on the subject (see e.g. BIS, 2015), the phrase "digital currencies" is used in the narrow sense of "cryptocurrencies". This definition excludes physical currencies such as notes, coins and local currencies. It excludes also both deposits with central and commercial banks and electronic money, which is recorded electronically on a stored-value card or other device, although both of them are kept like DCs in a digitalized format.

The various types of monetary instruments currently available are presented in a simplified manner in Table 1, adapted from Camera (2017).

Table 1: Types of monetary instruments

\section{Physical representation Digital representation}

\section{Denomination}

Legal unit Notes and coins Deposits, electronic money
Other units
Local currencies and tokens
Digital currencies

DCs can be seen as a combination of two elements (BIS, 2015; He et al., 2016):

- An asset, which is similar to a standard modern currency in the sense that it has no intrinsic value but which differs from legal currency to the extent that currently issued DCs are not backed by any issuer (for instance, the Bitcoin is nobody's liability), and that, a fortiori, it is not legal tender;

- An exchange mechanism which allows payment and settlement through the use of distributed ledger technology (DLT). A DL is a bookkeeping system which can be shared ("distributed") and updated in real time via a network of "nodes" (i.e. computers) in a secured manner. The best known DL is the Blockchain, in which data are organized as blocks chained by cryptographic techniques. In particular, DLs allow peer-to-peer exchanges of electronic value in the absence of trust between the parties and without the 
need for intermediaries. This is achieved through recourse to cryptography, which limits the risk of intrusion, through access of all users to the history, and through the requirement that each transaction in the DL is validated by DC users (so-called "consensus"), who can be expected to oppose any "double use" of DCs. As a consequence, each validated transaction increases the degree of certainty of previous transactions, enabling to reach quasi full certainty in a limited time (one hour, or six transactions, in the case of the Bitcoin, since the validation of each Bitcoin transaction takes ten minutes).

DC schemes operate along two different designs (BIS, 2015; ECB, 2015; ESMA, 2016; He et al., 2016):

- There are public (or decentralized, or open, or non-permission-based) systems, which incorporate an embedded currency, like the Bitcoin. In such systems, where users can obtain units by "mining" (i.e. validating transactions) or on the secondary market, the asset component of DCs plays an important role and the number of units that can be issued is usually set $e x$ ante (this is the case for the Bitcoin, although it seems the rule could be changed provided that a majority of the users would agree). The promised scarcity of the asset supports its price, which incentivizes the public to become users of the DC and miners to validate transactions. There is thus an inherent element of bubble in such schemes;

- There are also private (or centralized, or closed, or permission-based) systems. Such systems do not necessarily incorporate an embedded currency but always involve a DL: the exchange mechanism component of DCs is prevalent in them. "Miners" are usually not remunerated, and the process of validating transactions can be greatly simplified. In more detail, private systems can be of two sorts (Buterin, 2015; He et al., 2016): fully private systems in which write permissions are kept centralized to one organization, and hybrid (or consortium) systems in which the validation (also called "consensus") process is controlled by a pre-selected set of nodes. In both cases, read permissions can be, and usually are, restricted but the key feature, which is common to all private systems, is the a priori restriction of write permissions. This restriction is aimed at reducing the cost of operating the DL. It also eliminates the negative externality that arises in public systems as "miners" compete to validate transactions, implying a high consumption of energy. However, the more write and read permissions are centralized, the less the DL is "distributed", and thus the less the embedded currency can be considered as a DC. Also, private systems in which read permissions are restricted and the embedded currency is backed by an issuer can be regarded as e-money issuance schemes, even though they use DLT.

\subsection{Motives for a wider usage of digital currencies}

Motives could differ between the public and financial institutions.

As far as the public is concerned, it is important to note that DCs currently perform very poorly the three functions associated with money (Yermack, 2013; Ali et al., 2014): medium of exchange, unit of account and store of value. Very few merchants accept them as media of exchange; those retailers who accept them adjust prices in DCs according to their exchange rate fluctuations vis-àvis fiat currencies, which implies that DCs are not used as units of account; finally, their prices in fiat currencies have been far more volatile than those of national currency pairs, which does not make them proper stores of value. Furthermore, some technical issues, such as scalability, security 
concerns, interoperability, the possibility to cancel transactions - for instance, in case of fraud, although cancelling transactions does not fit well with the normal functioning of the Blockchain -, and the high energy consumption involved in the process of validating transactions, would have to be solved to enable a widespread usage of DCs. In the following, it is assumed that these technical difficulties have been overcome. However, Rysman and Shuh (2016) provide evidence that consumers are willing to adopt payment innovations with only limited applications, provided that these applications have clear and attractive use. In that context, several factors could support an increased demand for DCs by the public (BIS, 2015; He et al., 2016):

- DCs allow "pseudo-anonymity" (transactions can be made under pseudonyms), thus helping preserve privacy, especially in public systems. However, this argument is recursive in nature (it pre-supposes that most transactions are made in DCs, thus avoiding that purchases and sales of DCs can be traced on bank accounts. Furthermore, on the ground of privacy, paper currency can be preferred to DCs in hand-to-hand transactions, since it does not leave any mark, be it on a DL or elsewhere. Finally, if the usage of DCs became widespread, it is highly likely that public authorities would take steps to limit the negative consequences of "pseudo-anonymity" for the implementation of AML/CFT regulation. More generally, public DC schemes in particular appear unfitted for performing regulated activities, such as banking and insurance (Beaudemoulin et al., 2017), in which there is a need for a clear assignment of responsibilities;

- DCs can be acquired for speculative motives. This is presently the main motive supporting the demand for the most popular DC, Bitcoin (Böhme et al., 2015). However, this argument is predicated on the scarcity of supply, a factor in stark contrast with the wider usage of DCs as a medium of exchange, which would require an elastic supply. Besides, changing the rule governing the supply of DCs would likely be very difficult within current systems since this decision would have to be made by the users and would hurt their interests, as the value of DCs would then very probably fall;

- Finally, DCs can be used to make cheap and speedy payments at the global level. In fact, the main - if not the only - example of a wider usage of DCs by the public that is mentioned in the literature is in the sending of remittances: for small remittances, the cost with Bitcoin support is more than ten times lower than when using traditional service providers and the payment can be made in a matter of minutes instead of days. However, firms operating more traditional means of sending remittances could respond by cutting prices and have in fact started doing so (He et al., 2016). Above all, the use of DCs in the sending of remittances implies transactions costs and uncertainty both at the "entry" (purchase of DCs) and at the "exit" (resale of DCs), which can make it more expensive than standard payment services involving at most one exchange rate transaction, either at "entry" or "exit". In this case also, the argument in support of the use of DCs is of a recursive nature: it is valid only if this use is generalized, thus pre-supposing the condition it is supposed to justify.

It thus appears difficult, as this stage and even under the assumption that afore-mentioned technical difficulties have been overcome, to find credible motives which could support a spreading of DCs usage by the public beyond the sending of small remittances. As a consequence, network effects should continue to favor the usage of fiat currencies, instead of DCs. As a matter of fact, according to Cecchetti and Schoenholtz (2017), the primary use of DCs is to evade capital controls in an environment of financial repression, as recently exemplified by the increased use of Bitcoin in China and Venezuela. 
By comparison, the use of DL technology by financial institutions, within private DC schemes, is usually deemed far more promising to the extent that the cost of validating transactions can be kept sufficiently low (Brainard, 2016 ; ESMA, 2016; Gifford and Cheng, 2016; Goldman Sachs, 2016; He et al., 2016). In particular, the use of DLs would allow cost-cutting in international payments, financial markets infrastructures and post-trading activities by enabling to streamline procedures and to increase their secureness, thus lowering the headcount in the relevant activities, by reducing recourse to intermediaries, by improving the tracking of ownership and transactions, and by increasing the speediness of transactions and netting, thus reducing liquidity needs and capital charges. Furthermore, financial innovation would be promoted by the design of "smart contracts" (i.e. contracts that execute themselves automatically in case some pre-defined events materialize) supported by DLT. However, in all these instances, DC schemes at play would be centralized and would likely be used on an extensive basis only if there is a high degree of certainty on the value of the units used. This in turn requires that either transactions are executed extremely fast so that exchange rate risk is limited (case of a one-time use for small values, e.g. remittances), or that fiat currency (or tokens representing fiat currency) can be recorded on DL technology so that exchange rate risk is eliminated (case of a permanent use for large values, e.g. in the settlement and clearing of cash securities or in repo activities).

In the following, it is thus assumed that a widespread use of DCs, whether by the public or by financial institutions, would occur only if DCs were very close substitutes for fiat currency or were even representations of the fiat currency itself.

\section{Monetary policy consequences of a widespread usage of digital currencies}

A first sub-section describes three main scenarios in which the usage of DCs could become widespread and assesses qualitatively their respective likelihoods in the medium to long-term. A second sub-section envisages how monetary policy could be adjusted in response.

\subsection{Three main scenarios and their respective likelihoods}

In a first scenario, labeled A, financial institutions would use DCs only internally and between them, within private DC schemes. As a result of liquidity savings allowed by the use of DL technology, banks would demand fewer central bank reserves for the final settlement of their transactions. For reasons exposed in sub-section 1.2, this scenario can be seen as likely, provided some technical issues are solved.

In a second scenario, labeled B and possibly encouraged by authorities if the use of DCs was to spread in the public, there would be a convergence of DC schemes and banking activities, with DC schemes collecting deposits and distributing credit and/or banks issuing DCs. In the first case, DC schemes would at some point be submitted by the regulators to the same requirements as banks; in the second case, DCs would be backed by an issuer (a bank), thus differing greatly from current DCs such as Bitcoin. In both cases, the monetary consequences would vary according to the services provided by DCs: with minimum payment services provided, DCs could substitute for paper currency and unremunerated sight deposits (scenario B1); if DL technology enabled paying interest on DCs, they could also substitute for remunerated sight deposits and term deposits (scenario B2 which includes B1). In the following, we make the simplifying assumption that all bank deposits are remunerated. We also assume that scenario B includes A since the latter one is considered as likely. However, due to the superiority of cash vis-à-vis DCs in preserving privacy mentioned above, scenario B1can be seen as unlikely or at least remote: one 
would not wish everyone to have access on the DL to the use she has made of DCs (Kahn et al., 2005). Scenario B2 would thus be even more unlikely than scenario B1.

In a third scenario, labeled C and envisaged by Koning (2014), Broadbent (2016), Raskin and Yermack (2016) and Skingsley (2016), the central bank itself would issue central bank DC (CBDC). It is assumed that scenario $\mathrm{C}$ could materialize in two situations: either at the initiative of the central bank ${ }^{2}$, concomitantly with or following A ('offensive' strategy), or in response to scenario B ('defensive' strategy). The main merit of scenario C would lie in its high degree of credibility as the central bank is in a unique position to guarantee a fixed exchange rate between CBDC and fiat currency, since it can create both without limit (Andolfatto, 2015). The monetary consequences of scenario $\mathrm{C}$ would at least partly undo and at most reverse those of scenario $\mathrm{B}$. They would depend on who can have access to $\mathrm{CBDC}$ but also, as in $\mathrm{B}$, on the services provided by CBDC. If access to CBDC was reserved to banks within private DC schemes ${ }^{3}$ (scenario C1), the fall in the demand for reserves would be smaller than in scenario $\mathrm{A}^{4}$. To the extent that scenario A is seen as likely, scenario C1 can also be considered as likely. If access was open to the public (scenario C2 which is assumed to include C1 in the following, as it would be odd, and probably also difficult, to allow the public, and not banks, to use CBDC), then CBDC could also substitute for paper currency, as banks' DCs would in scenario B1, and possibly also to bank deposits. As a matter of fact, scenario $\mathrm{C} 2$ could be construed as part of a plan, together with the withdrawal of large denomination banknotes, to reduce progressively the use of traditional cash with a view to both making the financing of illegal transactions more difficult and to lowering the operating costs of managing the currency (Koning, 2014). Scenario C2 is seen as at most as likely as scenario B1. A last possibility (scenario C3 which is assumed to include C2 and thus also C1), which can be seen as a counterpart to scenario B2 with the central bank in the place of banks and DC schemes, would be for the central bank to give the public access to CBDC on which, as assumed above regarding banks' usage of CBDC, it would pay interest and pay credit. This scenario is seen as even less likely than scenario B2, for reasons which relate both to supply and demand. Regarding supply, scenario C3 would imply that the central bank competes directly with the banking sector, which central banks have refrained from doing since the switch from metallic currencies to fiat currencies, both in order to avoid a conflict of interest with their policy objectives and because competition would be unfair since the central bank benefits from seigniorage revenue. Regarding demand, in normal circumstances - i.e. in the absence of a run on private DCs -, there is no clear reason why the public would prefer using CBDC, issued by a

\footnotetext{
2 Carney (2016) mentions that the Bank of England explores the use of DL technology in its core activities, including the operation of RTGS, with a view to enhancing resilience; in Sweden, where the nominal demand for cash has been falling by nearly 40\% between 2007 and 2016, Skingsley (2016) states that the central bank is going in the coming years, to investigate the issuance of an electronic or a digital currency, in parallel with paper currency.

3 This approach differs from the one of Barrdear and Kumhof (2016) who envisage that a CBDC could be issued as a sort of parallel currency against an equal amount of government debt, at par with the fiat currency, interest-bearing without providing other banking services, held only by non-banks, preferably weakly substitutable for bank deposits, and used by the central bank as a second monetary policy instrument by varying the quantity issued or the spread with the policy rate. Furthermore, Barrdear and Kumhof (2016) do not take reserves, banknotes or private DCs into consideration. In fact, the system they describe would rather qualify as a central bank e-money issuance scheme (sub-section 1.1), with the difference, stressed by the authors, that the DL, with restricted write and read permissions, would nevertheless allow policymakers access to the entire history of transactions, a feature which is viewed here as detrimental to privacy and thus to the success of CBDC (sub-sections 1.1 and 2.1).

${ }^{4}$ In fact, such a fall might not even occur if, as already contemplated by the Bank of England (Carney, 2016), payment service providers get access to central bank money, be it under the traditional form or under the form of CBDC.
} 
government agency, rather than private DCs, and get loans from the central bank rather from their usual loan providers, with whom they have long-standing relationships ${ }^{5}$.

The three scenarios and their respective likelihoods are summarized in the Table 2 below where:

- Changes are indicated by signs, in comparison with a scenario where there would be no use of DCs by financial institutions internally or by the public (i.e. basically the current situation);

- The demand for central bank reserves is supposed not to be satiated, as can occur after asset purchases by the central bank (if this were the case, there would be no impact on the demand for reserves in any scenario until, due for instance to the issuance of CBDC or to the unwinding the central bank asset purchases, a demand for central bank reserves reappears);

- As detailed above, it is assumed that each scenario, except scenario A, includes the previous one(s), in the lexicographic sense. One exception is scenario C1 which could occur concomitantly with A;

- Banks and DC schemes are merged together in scenarios B and C since, as mentioned above, DC schemes would be submitted by the regulators to the same requirements as banks in case DCs systems would provide the same services as banks;

- CBDC is regarded as central bank reserves and is thus assumed to be on the central bank balance sheet;

- In scenario C1, it is assumed, for simplifying reasons, that the impact of the issuance of CBDC on the demand for central bank reserves is at most neutral. In other words, even if the use of CBDC may be more efficient than the one of reserves, as suggested by Broadbent (2016), this is assumed not to prompt banks or other financial institutions that would have access to CBDC, to settle in CBDC enough transactions, which they otherwise would have settled outside the central bank, for the demand for reserves, including CBDC, to increase (in other words, there would be no 'crowding in' effects).

\footnotetext{
${ }^{5}$ Koning (2014) suggests that, in order to encourage the use of CBDC, the central bank could be spared from "Know Your Customer" (KYC) rules, just as it is currently for the use of cash. However, the comparison is not fully convincing as knowing the users of cash would be extremely difficult whereas knowing the users of CBDC would be immediate for the central bank. Furthermore, exempting the central bank from KYC rules in the case of CBDC would both create a level-playing field difficulty and leave the issue of read permissions -at least the reading of the central bank - unsolved, which many in the public may dislike.
} 
Table 2: Scenarios for the spreading of digital currencies

\begin{tabular}{|c|c|c|c|c|c|c|c|}
\hline \multirow{2}{*}{\multicolumn{2}{|c|}{ Scenario }} & \multirow{2}{*}{$\begin{array}{c}\text { Probability } \\
\text { of } \\
\text { occurrence }\end{array}$} & \multicolumn{3}{|c|}{ Impact on demand } & \multicolumn{2}{|c|}{$\begin{array}{c}\text { Impact on the } \\
\text { size of balance } \\
\text { sheet }\end{array}$} \\
\hline & & & $\begin{array}{l}\text { Central } \\
\text { bank } \\
\text { reserves }\end{array}$ & $\begin{array}{c}\text { Paper } \\
\text { currency }\end{array}$ & Deposits & $\begin{array}{c}\text { Central } \\
\text { bank }\end{array}$ & Banks \\
\hline \multicolumn{2}{|c|}{$\begin{array}{c}\text { A } \\
\text { Internal use }\end{array}$} & High & - & $\begin{array}{l}\text { Not } \\
\text { relevant }\end{array}$ & $\begin{array}{l}\text { Not } \\
\text { relevant }\end{array}$ & - & - \\
\hline \multirow{2}{*}{$\begin{array}{c}\text { B } \\
\text { Convergence }\end{array}$} & $\begin{array}{c}\text { B1 } \\
\text { Minimum } \\
\text { services }\end{array}$ & Low & - & - & $\begin{array}{l}\text { Not } \\
\text { relevant }\end{array}$ & - & + \\
\hline & $\begin{array}{c}\text { B2 } \\
\text { Full banking } \\
\text { services }\end{array}$ & Very low & - & - & - & - & + \\
\hline \multirow{3}{*}{$\begin{array}{c}\text { C } \\
\text { Central Bank } \\
\text { Digital } \\
\text { Currency }\end{array}$} & $\begin{array}{c}\text { C1 } \\
\text { No access by } \\
\text { the public }\end{array}$ & High/Medium & $-1=$ & $\begin{array}{l}\text { Not } \\
\text { relevant }\end{array}$ & $\begin{array}{l}\text { Not } \\
\text { relevant }\end{array}$ & $-/=$ & - \\
\hline & $\begin{array}{c}\mathrm{C} 2 \\
\text { Minimum } \\
\text { services }\end{array}$ & Low & $?$ & - & - & $?$ & $?$ \\
\hline & $\begin{array}{c}\text { C3 } \\
\text { Full banking } \\
\text { services }\end{array}$ & Extremely low & $?$ & - & - & $?$ & $?$ \\
\hline
\end{tabular}

\subsection{Monetary policy adjustments}

Whichever scenario materializes, it is important to keep in mind that, as seen in sub-section 1.2, a widespread use of DCs would likely occur only if DCs were very close substitutes for fiat currency or were even representations of the fiat currency itself. This has an important monetary policy consequence: the central bank would still be able to set the level of a given - usually very shortterm - interest rate that would be relevant for the economy, including for DC users. This would be the case even if the usage of DCs would spread to the point that there would be no demand for fiat currency or central bank reserves. As shown by Woodford (2001), the only difference would then be that the central bank would collect deposits at an interest rate that would provide a ceiling - instead of a floor currently - to the overnight rate: for monetary policy to have potency, it is sufficient that the liability issued by the central bank should perform the role of a unit of account. However, an issue that would arise would then be how the central bank could cover its expenses: in particular, depending on a subsidy from Government would likely entail a loss of independence of the central bank at some point in time.

In more detail, according to how the balance sheets of the central bank and banks are impacted (Table 2), and thus according to which scenario prevails (sub-section 2.2.1), the monetary policy consequences would differ (sub-section 2.2.2).

\subsubsection{Balance sheets impacts according to the three scenarios}

In scenario A, the substitution between DCs and central bank reserves would imply a shrinking in the sizes of the balance sheets of both the central bank and banks (scenario C1 at least partly undoes that). 
In scenario $\mathrm{B}$, just as in scenario $\mathrm{A}$, the size of the central bank balance sheet shrinks. However, it does so more than in scenario A because DCs substitute for paper currency and also, mainly in scenario B2, because the base of reserve requirements is eroded by the fall in deposits. Correspondingly, the size of the banking sector balance sheet - including DC schemes - increases.

Scenario C offsets at least partly the impact of scenario B on the demand for reserves, possibly even reversing it to the extent that the success of CBDC vis-à-vis the public in scenarios $\mathrm{C} 2$ and C3 would more than offset the lesser demand for cash and deposits (in the latter case, due to the impact on required reserves). This reflects the fact that, in spite of a lesser demand for paper currency and a narrower base for reserve requirements, banks would have to "purchase" CBDC just as they "purchase" banknotes, i.e. by getting refinanced. As the issuer of CBDC, the latter being outside money just as banknotes are currently, the central bank would not be in a position to refuse to accommodate ("refinance") the demand for CBDC, provided of course enough collateral is posted by financial institutions having access to refinancing. On this point, our assessment differs from the one of Broadbent (2016) and Raskin and Yermack (2016). By assessing that the banking sector might have to reduce its assets or at least would see its capacity to make loans impaired following the issuance of CBDC, these authors seem to implicitly assume that the central bank might not accommodate the demand for CBDC. In fact, in scenarios C2 and C3, refinancing by the central bank would just replace deposits in the balance sheets of banks ${ }^{6}$. Overall, the sign of the impact of scenarios C2 and C3 on the size of the central bank balance sheet is unclear and depends on the extent to which the public shifts into CBDC, out of banknotes (which should take place only to a limited extent due to the superiority of banknotes vis-à-vis DCs in protecting privacy), private DCs (which is possible if agents view CBDC as more reliable than private DCs) and bank deposits (which is more unlikely unless there is a bank run, since it is unlikely that agents would "vote" in favor of a bank monopoly and/or would think the central bank would better protect privacy than a commercial bank). However, this impact on the size of the central bank balance sheet should be less negative - or more positive - in scenario C3 than in scenario C2. Correspondingly, the impact on the sign of the change in the size of the balance sheet of the banking sector is also unclear, although it should be more negative in scenario C3 than in scenario C2. In the extreme, in scenario C3, if the public were to exchange its entire bank deposits for CBDC and get all its loans from the central bank, the banking system would disappear. Such a situation, which Raskin and Yermack (2016) dub "financial socialism", is nevertheless very unlikely to occur, as explained in sub-section 2.1.

\subsubsection{Consequences for monetary policy}

A distinction is drawn between consequences for monetary policy strategy (i), conduct (ii) and instruments (iii) (Drumetz et al., 2015). On the two latter aspects, some consequences are very similar to those deriving from the use of e-money (BIS, 1996). This is unsurprising to the extent that private DC schemes are very similar to e-money schemes, as mentioned above (sub-section 1.1).

\section{(i) Monetary policy strategy}

A policy challenge that has been mentioned is that, due the limited supply of DCs, their widespread usage would inflict a deflationary bias in a growing economy (He et al., 2016).

\footnotetext{
${ }^{6}$ More worrisome for banks would be that they would lose access to the information retrieved from the management of the deposit accounts of their customers. They would thus have to acquire this information, e.g. from payment service providers, and their loss of informational capital would be reflected in the prices of the securities they issue. This is precisely why scenarios C2 and C3 are seen as unlikely (sub-section 2.1).
} 
Furthermore, the inflexibility of the supply of DCs would create difficulties to smooth the business cycle (He et al., 2016). However, both views are based on the same recursive line of reasoning as the one put forward regarding the use of DCs in international payments (sub-section 1.2): it pre-supposes a wide use of DCs in spite of their poor monetary performances in comparison with fiat currencies. Why would private agents adopt in the first place new currencies clearly unfit to fulfill correctly a role as medium of exchange, unit of account and store of value due to inelasticity of supply?

In the same vein, it can be envisaged that, in a situation where the substitution away from deposits and cash into DCs would be very large and, at the same time, the interconnection between the users of sovereign currencies and the users of DCs would be very weak, then monetary policy would lose its potency (BIS, 2015). Such a scenario is not envisaged above since it is based on a dichotomy that seems artificial: for which reason would a substantial proportion of agents shift out of fiat currencies into DCs that are not linked to them? And why should these agents not interact with other agents? In fact, such a scenario could only be envisaged if there was a large loss in the credibility of sovereign currencies. This loss in credibility would even have to be common to all major currencies since a lack of trust in the national currency usually leads to a dollarization or euroisation of the economy?

Finally, Bordo and Levin (2017) submit that, in C3 scenario type, the central bank could target a zero long-run average inflation rate. Their proposal stems from the possibility the central bank would seemingly have, if it issued remunerated CBDC, to set negative interest rates (sub-section 2.2.2 ii). However, apart from the existence of an effective zero lower bound as a result of the issuance of unremunerated currency by the central bank, there are other reasons - such as the absence of a permanent price optimization process, the desire to facilitate relative price adjustments, and biases in the measurement of inflation - for setting a slightly positive inflation target (Drumetz et al., 2015). Besides, according to Friedman (1960), whom the authors refer to, the difficulties to remunerate currency would justify pursuing a negative inflation target rather than a zero one. Supposing the issuance of CBDC would make these difficulties disappear (subsection 2.2.2 ii), then a slight upward revision of the inflation target would seem warranted (Pfister and Valla, 2017). Finally, in the scheme the authors envisage, individuals would have to open accounts with the central bank which would strictly protect the privacy of all their transactions: this looks like a central bank electronic money issuance scheme rather than a CBDC issuance one (sub-section 1.1 and footnote 3 ).

Conduct of monetary policy

Four issues arise:

- Regarding monetary policy indicators, would not the informative content of monetary (i.e. money and credit) aggregates be reduced by the substitution away from deposits into DCs? This could transitorily be the case but the standard approach to deal with a financial innovation which affects money aggregates is to modify their definition, broadening it to include the new assets that are similar to the monetary assets they substitute for, in this case DCs, whose schemes would be subjected to reporting requirements (see BIS, 1996, on the similar case of electronic money). Correspondingly, in scenario B, credit aggregates could be broadened by subjecting DC schemes to reporting requirements. Supposing

\footnotetext{
${ }^{7}$ However, the case of Cyprus in 2011 where, following the implementation of capital controls, holders of deposits in Cypriot banks bought Bitcoins, leading to a sharp appreciation of the digital currency, shows that central banks are faced with increased currency competition (Andolfatto, 2016).
} 
however that DCs allow non-financial agents to save liquidity, as previously noted for financial institutions, then the stability of the relationship between money and activity could be jeopardized in a more significant and lasting manner;

- Regarding the transmission mechanism, would it be affected? In all scenarios, the use of DLT by financial institutions should modify the roles of bank capital and funding costs in the credit channel of monetary policy, since liquidity needs and capital charges would be reduced (sub-section 1.1). One consequence would be to release collateral, leading to a potential lowering of the liquidity premiums on Treasuries and thus to higher market interest rates (Andolfatto, 2016). Furthermore, the increased speed of transactions, as well as the execution of "smart contracts", could contribute to a faster transmission in the interest rate channel. Finally, in scenarios C2 and C3, the transmission mechanism could also become more rapid if central bank refinancing increased (the opposite conclusion would apply in all other scenarios, where the demand for reserves would decline). However, all these developments would more likely lead to one-time and limited adjustments in the transmission mechanism;

- Regarding the setting of interest rates, would CBDC enable the central bank to implement significantly negative interest rates (Koning, 2014; Haldane, 2015; Broadbent, 2016; Raskin and Yermack, 2016; Bordo and Levin, 2017)? This would indeed seem to be easier in case the usage of DCs was widespread, provided of course that DLT would allow the payment of negative interest rates. However, the problem of paper currency creating an "effective" lower bound, i.e. a negative interest rate at which agents start to effectively exchange deposits for cash, would only be solved either if, as noted by Broadbent (2016), the central bank abolished cash, exchanging it in scenarios C2 and C3 for CBDC, or if an exchange rate was created for paper currency (Pfister and Valla, 2017);

- Regarding the role of the central bank as a lender of last resort (LoLR), would it be compromised? Here, the issue not whether DC schemes could replace central banks, as surmised by He et al. (2016), since it has been assumed, in scenario B, that there would be a convergence of banks and DC schemes: as the latter ones would become very similar to banks, they would likely be granted access to the LoLR. The issue is rather that, in scenarios C2 and C3, central bank refinancing might represent a large share of banks' liabilities, in the however unlikely case where the public would widely adopt CBDC in lieu of private DCs and deposits 8 . Also, issuing CBDC would lower the frictions involved in running to central bank money, thus exacerbating liquidity risk (Niepelt, 2015; Carney, 2016). For both reasons, it might then become more difficult than currently for the central bank to refuse a bank LoLR assistance. The risk of having too much LoLR rather than not enough would thus be another reason, on top of the current ones to limit moral hazard considerations inherent to the conduct of LoLR operations, by making access to these operations more rule-based (Pfister and Valla, 2017).

8 This scenario has sometimes been seen as a step in the direction of a "narrower" banking system (Broadbent, 2016; Raskin and Yermack, 2016), which some authors deem more prone to stability than the existing one (see e.g. Pennachi, 2012). However, it would differ fundamentally since maturity transformation would be kept unchanged: there would be a substitution within the liabilities of banks (central bank refinancing instead of deposits) rather than within their assets (reserves instead of loans, like for instance in the Chicago Plan; Phillips, 1996). Furthermore, this substitution would leave maturity transformation by banks unchanged if central bank refinancing is granted at a short-term maturity, as is usually the case. 
Monetary policy instruments are of two sorts: reserve requirements which serve to enlarge the demand for reserves and interest rate instruments (open market operations and standing facilities) which serve to signal the monetary policy stance (Drumetz et al., 2015.

In case the demand for reserves would decline substantially (scenario A, B1 and above all B2), the central bank could react in several manners:

- It could broaden the base of reserve requirements by including DCs. This would be logical in scenario $\mathrm{B}$, in the face of the convergence between banks and DC schemes;

- It could raise reserve ratios, although this would penalize deposits vis-à-vis DCs unless the base of reserve requirements is also broadened;

- It could enlarge the demand for reserves by issuing CBDC (scenario C), just like it has been envisaged that it could issue e-money in response to a substitution of private emoney for cash (BIS, 1996);

- It could finally choose to implement monetary policy by withdrawing rather than supplying liquidity, although this may create difficulties to cover expenses and ultimately for the central bank independence.

Regarding interest rate instruments, the issue arises in scenario $C$ as to which rate the central bank could choose for the remuneration of CBDC (Mersch, 2017). This rate could be the one on excess reserves (the deposit facility rate within the Eurosystem), in order to avoid create arbitrage opportunities between CBDC and standard reserves, or slightly below to take the broader payment services provided by CBDC into account. However, in scenarios $\mathrm{C} 1$ and $\mathrm{C} 2$, interests on CBDC could be paid only to financial institutions, if the central bank wishes not to encourage a substitution into CBDC out of currency. Finally, one can envisage a scenario which would be intermediate between scenarios $\mathrm{C} 2$ and $\mathrm{C} 3$, in which CBDC available to financial institutions and the public would be remunerated at or slightly below the interest rate on excess reserves but would not provide other banking services. This would avoid arbitrage between CBDC and paper currency in case the central bank, as a way to implement interest rates below the effective ZLB, would introduce an exchange rate for paper currency (Pfister and Valla, 2017). This would also circumvent the tricky technical concern of the central bank having to set a rate on its loans to the broader public, which could differ from the one on its loans to non-financial institutions and would de facto become a policy rate, raising the issue of the spread between the two rates, with the risk of sending conflicting signals and of distorting the competition with the private sector for the distribution of loans.

\section{Conclusions}

The use of DCs could most likely spread only under conditions that would leave basically unchanged the capacity of the central bank to pursue an identical inflation target in the same manner as nowadays, by setting an interest rate level. However, some adjustments may have to be made to the definition of monetary aggregates and possibly also to the base and/or ratio of reserve requirements. Even in the most extreme and unlikely scenario, where the central bank would issue CBDC with deposit attributes and the public would massively adopt it, banks' role in distributing credit should not be seriously impaired. Banks might rather become very dependent on central bank refinancing, which would call for a pre-announced rule-based LoLR policy in order to limit moral hazard considerations (Pfister and Valla, 2017). Banks would disappear only in the limit case scenario of "financial socialism" (Raskin and Yermack, 2016). However, the 
decision to embark into such a scenario would be highly political and would not necessarily be accepted by the public. 


\section{References}

Ali R., Barrdear J., Clews R., Southgate J. (2014), "Innovations in payment technologies and the emergence of digital currencies", Quarterly Bulletin, Q3, Bank of England, 1-11, http://www.bankofengland.co.uk/publications/Documents/quarterlybulletin/2014/qb14q301.pd f.

Andolfatto D. (2015), "Fedcoin: On the Desirability of a Government Cryptocurrency", MacroMania blog, 3 February, http://andolfatto.blogspot.fr/search?q=Fedcoin.

Andolfatto D. (2016), "Monetary policy implications of blockchain technology", MacroMania blog, 1 May, http://andolfatto.blogspot.fr/2016/05/monetary-policy-implications-of.html.

Bank for International Settlements (1996), Implications for central banks of the development of electronic money, October, http://www.bis.org/publ/bisp01.pdf.

Bank for International Settlements (2015), Digital currencies, Committee on Payments and Market Infrastructures, November, http://www.bis.org/cpmi/publ/d137.pdf.

Barrdear J., Kumhof M. (2016), "The macroeconomics of central bank issued digital currencies", Staff Working Paper, n 605, Bank of England, http://www.bankofengland.co.uk/research/Pages/workingpapers/2016/swp605.aspx.

Beaudemoulin N., Bedouin T., Warzee D. (2017), “Les enjeux de la Blockchain”, Réalités industrielles - Les Annales des Mines, forthcoming.

Böhme R., Christin N., Edelman B., Moore T. (2015), "Bitcoin: Economics, Technology, and Govenance", Journal of Economic Perspectives, 29(2), 213-238.

Bordo M., Levin A. (2017), "Central Bank Digital Currency and the Future of Monetary Policy”, May, http://www.hoover.org/sites/default/files/bordolevin bullets for hoover may2017.pdf?utm source=Institutional+Subscribers\&utm campaign= 95b9cc6053-Newsletter 2203 2017\&utm medium $=$ email\&utm term $=0$ 2dfc79416395b9cc6053-188508457.

Brainard L. (2016), "Distributed Ledger Technology: Implications for Payments, Clearing, and Settlement", Remarks at Institute of International Finance Annual Meeting Panel on Blockchain, 7 October, Washington, D.C., Board of Governors of the Federal Reserve System, http://www.federalreserve.gov/newsevents/speech/brainard20161007a.htm.

Broadbent B. (2016), "Central banks and digital currencies", Speech at the London School of Economics, 2 March, Bank of England, http://www.bankofengland.co.uk/publications/Documents/speeches/2016/speech886.pdf.

Buterin V. (2015), "On Public and Private Blockchains", Ethereum Blog, 7 August, https://blog.ethereum.org/2015/08/07/on-public-and-private-blockchains/.

Camera G. (2017), "A perspective on electronic alternatives to traditional currencies", Sveriges Riksbank Economic Review, 1, 126-148, http://www.riksbank.se/Documents/Rapporter/POV/2017/rap pov 170120 eng.pdf.

Carney M. (2016), "Enabling the FinTech transformation: Revolution, Restoration, or Reformation?", Speech that was to have been given at the Lord Mayor's Banquet and Merchants of the City of London at the Mansion House, London, 16 June, Bank of England, http://www.bankofengland.co.uk/publications/Documents/speeches/2016/speech914.pdf.

Cecchetti S., Schoenholtz K. L. (2017), "What Bitcoin Has Become", http://www.moneyandbanking.com/commentary/2017/1/22/what-bitcoin-hasbecome?utm source $=$ Institutional + Subscribers\&utm campaign $=95 \mathrm{~b} 9 \mathrm{cc} 6053$ Newsletter 2203 2017\&utm medium=email\&utm term $=0$ 2dfc794163-95b9cc6053188508457.

Drumetz F., Pfister C., Sahuc J.-G. (2015), Politique monétaire, de Boeck. 
European Central Bank (2015), Virtual currency schemes - a further analysis, https://www.ecb.europa.eu/pub/pdf/other/virtualcurrencyschemesen.pdf.

European Securities and Markets Authority (2016), The Distributed Ledger Technology Applied to Securities Markets, Discussion Paper,

https://www.ecb.europa.eu/pub/pdf/other/virtualcurrencyschemesen.pdf.

Friedman M. (1960), A Programme for Monetary Stability, Fordham University Press, New York.

Gilford K., Cheng J. (2016), "Implementation of real-time settlement for banks using decentralized ledger technology: policy and legal implications", Financial Stability Review, 20, Banque de France, 143-150, https://www.banque-

france.fr/fileadmin/user upload/banque de france/publications/Revue de la stabilite financie re/RSF20/RSF20_14_Gifford.pdf.

Goldman Sachs (2016), Blockchain - Putting Theory into Practice, Profiles in Innovation, Equity Research, May 24.

Haldane A. (2015), "How low can you go", Speech at the Portadown Chamber of Commerce, Northern Ireland, 18 September, Bank of England, http://www.bankofengland.co.uk/publications/Pages/speeches/2015/840.aspx.

He D., Habermeier K., Leckow R., Haksar V., Almeida Y., Kashima M., Kyriakos-Saad N., Oura H., Saadi Sedik T., Stetsenko N., Verdugo-Yepes C. (2016), "Virtual Currencies and Beyond: Initial Considerations", IMF Staff Discussion No. 16/03, International Monetary Fund, http://www.imf.org/external/pubs/ft/sdn/2016/sdn1603.pdf.

Kahn C. M., McAndrews J., Roberds W. (2005), "Money Is Privacy”, International Economic Review, 46(2), 377-399.

Koning J. P. (2014), "Fedcoin”, Moneyness blog, 19 October, http://jpkoning.blogspot.fr/2014/10/fedcoin.html.

Mersch Y. (2017), "Digital Base Money: An Assessment from the ECB's Perspective”, Speech for the farewell ceremony in the honor of Pentti Hakkarainen, deputy-Governor of Suomen Pankki - Finlands, January 16, http://www.ecb.europa.eu/press/key/date/2017/html/sp170116.en.html.

Niepelt D. (2015), "Reserves for everyone - towards a new monetary regime?”, VOX, 21 January, http://voxeu.org/article/keep-cash-let-public-hold-central-bank-reserves.

Pennachi G. (2012), "Narrow banking", Annual Review of Financial Economics, 4, 141-159.

Pfister C., Valla N. (2017), “'Nouvelle Normale' ou 'Nouvelle Orthodoxie’? Éléments d'un nouveau cadre d'action pour les banques centrales", Revue économique, forthcoming.

Phillips R. (1996), "The Chicago Plan and New Deal banking reform", in Stability in the Financial System, ed. D. Papadimitriou, New York, Macmillan.

Raskin M., Yermack D. (2016), "Digital Currencies, Decentralized Ledgers, and the Future of Central Banking", NBER Working Paper $n^{\circ}$ 22238, National Bureau of Economic Research.

Rysman M., Schuh S. (2016), "New Innovations in Payments", NBER Working Paper $n^{\circ}$ 22358, National Bureau of Economic Research.

Skingsley C. (2016), "Should the Riksbank issue e-krona?", Speech to the FinTech Stockholm 2016, Berns, 16 November, http://www.riksbank.se/Documents/Tal/Skingsley/2016/tal_skingsley 161116 eng.pdf.

Woodford M. (2001), "Monetary Policy in the Information Economy", in Economic Policy for the Information Economy, Federal Reserve Bank of Kansas City, Kansas City, 297-370.

Yermack D. (2013), “Is Bitcoin a Real Currency? An Economic Appraisal”, NBER Working Paper $n^{\circ}$ 19747, National Bureau of Economic Research 